\title{
GAMBARAN TINGKAT KARIES BERDASARKAN STATUS KEBERSIHAN GIGI DAN MULUT PADA ANAK USIA 12-13 TAHUN DI SMP KATOLIK SANTO YOHANIS PENGINJIL DESA LAIKIT MINAHASA UTARA
}

\author{
${ }^{1}$ Putri R. Dengah \\ ${ }^{2}$ Ni Wayan Mariati \\ ${ }^{2}$ Juliatri \\ ${ }^{1}$ Kandidat Skripsi Program Studi Pendidikan Dokter Gigi Fakultas Kedokteran \\ ${ }^{2}$ Program Studi Pendidikan Dokter Gigi Fakultas Kedokteran \\ Universitas Sam Ratulangi Manado \\ Email: dengahputri@yahoo.com
}

\begin{abstract}
Dental caries is a major problem in the oral cavity and can be found in all age groups. One of the causes of dental caries is poor oral hygiene. This study aimed to determine the level of caries and oral hygiene status in children aged 12-13 years in Junior High School St. Yohanis Laikit Village North Minahasa. Status caries and oral hygiene can be assessed using DMF-T index according to WHO and OHI-S is the score or the value of dental and oral examination according to Greene and Vermillion by summing Debris index (DI) and Calculus index (CI). This was a descriptive study conducted in Junior High School Santo Yohanis Laikit Village North Minahasa class 7 and 8. In general, the students belonged to the age group of 12-13 year olds. The total sample consisted of 57 students. The technique of sampling used total sampling. The results showed that the average DMF-T index was 2 (WHO categorized as low category), the average OHI-S index was 1.4 (WHO categorized as medium category. Conclusion: The status of caries and oral hygiene of Junior High School students of St. Yohanis Laikit village belonged to the medium category. Based on the dental and oral hygiene, the highest percentage of caries was in the medium category.
\end{abstract}

Keywords: caries, oral hygiene, student junior high school.

\begin{abstract}
Abstrak: Karies gigi merupakan masalah utama pada rongga mulut dan dapat ditemukan pada semua golongan umur. Salah satu penyebab karies yaitu kebersihan gigi dan mulut yang buruk. Penelitian ini bertujuan untuk mengetahui tingkat karies dan status kebersihan gigi dan mulut pada anak usia 12-13 tahun di SMP Santo Yohanis Penginjil Desa Laikit Minahasa Utara. Status karies dan kebersihan gigi dan mulut dapat dinilai menggunakan indeks DMF-T menurut WHO dan OHI-S merupakan skor atau nilai pemeriksaan gigi dan mulut menurut Greene and Vermillion dengan menjumlahkan Debris index (DI) dan Calculus index (CI). Penelitian ini bersifat deskriptif dan dilakukan di SMP Santo Yohanis Penginjil Desa Laikit Minahasa Utara kelas 7 dan 8 yang pada umumnya merupakan kelompok remaja umur 12-13 tahun dengan jumlah sampel sebanyak 57 orang. Teknik pengambilan sampel menggunakan total sampling. Hasil penelitian menunjukkan indeks DMF-T rata-rata sebesar 2 (dalam kategori WHO termasuk kategori rendah) dan indeks OHI-S rata-rata sebesar 1,4 (dalam kategori WHO termasuk dalam kategori sedang). Simpulan: Status karies dan kebersihan gigi dan mulut siswa SMP Santo Yohanis Penginjil Desa Laikit termasuk dalam kategori sedang. Berdasarkan status kebersihan gigi dan mulut, presentase karies terbanyak terdapat pada kategori sedang.
\end{abstract}

Kata kunci: karies, kebersihan gigi dan mulut, siswa smp. 
Karies adalah suatu penyakit jaringan keras gigi yaitu email, dentin dan sementum yang disebabkan oleh aktivitas suatu jasad renik dalam karbohidrat yang dapat diragikan, Proses terjadinya karies ditandai dengan timbulnya white spot pada permukaan gigi dan jika tidak dirawat akan berkembang menjadi karies. ${ }^{1}$ Karies gigi merupakan masalah utama pada rongga mulut dan dapat ditemukan pada semua golongan umur. $^{2}$

Sebanyak 98\% dari penduduk dunia pernah mengalami karies. Angka nasional untuk karies gigi usia 12 tahun mencapai 76,69\% dengan indeks DMF-T rata-rata 2,21. Berdasarkan data WHO tahun 2012, di seluruh dunia 60-90\% anak sekolah dan hampir $100 \%$ orang dewasa memiliki karies yang sering menimbulkan rasa sakit serta dapat memengaruhi kualitas hidup. ${ }^{3}$ Menurut Riskesdas tahun 2013 terjadi peningkatan prevalensi terjadinya karies aktif pada penduduk Indonesia dibandingkan tahun 2007 lalu, yaitu dari 43,4\% menjadi 53,2\% mengalami karies aktif, karies yang belum ditangani atau belum dilakukan penambalan, maka di Indonesia terdapat 93.998.727 jiwa yang menderita karies aktif. ${ }^{4}$

Salah satu faktor penyebab karies gigi yaitu kebersihan gigi dan mulut yang buruk. Untuk dapat menilai status kebersihan gigi dan mulut digunakan Oral Hygiene Index Simplified (OHI-S). Oral Hygiene Index Simplified merupakan 90 skor atau nilai pemeriksaan gigi dan mulut menurut Greene and Vermillion dengan menjumlahkan Debris Index (DI) dan Calculus Index (CI). ${ }^{5,6}$ Pada tahun 2012 di Manado, Virginia melakukan penelitian mengenai hubungan antara status kebersihan gigi dan mulut dengan karies siswa Sekolah Menengah Atas Negeri 1 Manado dengan hasil penelitian status kebersihan gigi dan mulut termasuk kategori sedang, status karies termasuk kategori tinggi dan tidak dapat hubungan yang bermakna. ${ }^{7}$ Berdasarkan alasan-alasan tersebut di atas penulis tertarik untuk meneliti suatu permasalahan yaitu gambaran tingkat karies berdasarkan status kebersihan gigi dan mulut pada anak usia 12-13 tahun di SMP Katolik Santo Yohanis Penginjil Desa Laikit Minahasa Utara. Peneliti memilih sekolah di desa tersebut karena belum pernah dilakukan penelitian yang berkaitan dengan kesehatan gigi dan mulut khususnya tingkat karies berdasarkan status kebersihan gigi dan mulut.

\section{BAHAN DAN METODE PENELITIAN}

Penelitian ini merupakan penelitian deskriptif. Penelitian dilakukan di SMP Katolik Santo Yohanis Penginjil Desa Laikit Minahasa Utara, pada bulan Juli 2015. Populasi penelitian ialah seluruh anak kelas 7 dan 8 di SMP Katolik Santo Yohanis Penginjil Desa Laikit Minahasa Utara yang berjumlah 72 siswa.

Penelitian ini menggunakan metode total sampling, yaitu mengambil semua siswa untuk pemeriksaan dan yang memenuhi kriteria inklusi. Variabel penelitian ialah karies dan kebersihan mulut. Penelitian ini dilaksanakan kurang lebih satu minggu. Pemeriksaan yang dilakukan dengan tim berjumlah 7 orang yang telah dilakukan persamaan persepsi dengan tim. Tim terdiri dari 3 orang operator, 3 orang asisten operator dan 1 orang untuk sterilisasi. Dalam kelompok pemeriksa 1 pasang terdiri dari 2 orang, yang bertugas memeriksa rongga mulut dan mencatat hasil pemeriksaan. Pemeriksaan dilakukan langsung di dalam rongga mulut menggunakan kaca mulut, sonde dan ekskavator, alat diagnostik yang disediakan berjumlah 20 set.

Pemeriksaan status karies (DMF-T) serta status kebersihan gigi dan mulut (OHI-S) pada responden. Langkah-langkah pemeriksaan status DMF-T dan OHI-S yaitu sebagai berikut, operator melakukan persiapan berupa mencuci tangan menggunakan sabun pada air mengalir, kemudian operator mengenakan alat pelindung diri yaitu masker, sarung tangan dan baju pelindung. Responden diminta untuk tenang dan berkumur menggunakan air kemasan yang telah disediakan, kemudian subjek diinstruksikan untuk membuka mulut agar terlihat rongga 
mulutnya kemudian subjek diperiksa apakah ada gigi yang rusak, gigi yang ditumpat atau ditambal, dan gigi yang telah tanggal. Setelah itu subjek juga diperiksa kebersihan gigi dan mulutnya untuk melihat apakah ada debris dan kalkulus pada permukaan insisal atau oklusal gigi 16, 11, 26, 36, 31 dan 46. Operator dibantu oleh asisten yang bertugas untuk melakukan pengisian formulir pemeriksaan DMF-T dan OHI-S. Selama melakukan pemeriksaan, operator tetap berhati-hati terhadap kontak dengan cairan atau darah dari responden. Pengumpulan data dilakukan sampai tercapainya jumlah sampel yang dibutuhkan dalam penelitian. Data diolah dan dideskripsikan berdasarkan distribusi frekuensi dan disajikan dalam bentuk tabel.

\section{HASIL PENELITIAN}

Jumlah subjek penelitian berjumlah 72 orang, tetapi yang terjangkau hanya 57 orang terdiri dari laki-laki 29 orang (51\%) dan perempuan 28 orang (49\%). Siswasiswi yang diteliti berusia 12-13 tahun, yakni 42 orang berusia 12 tahun (74\%) dan 15 orang (26\%) berusia 13 tahun. (Tabel 1).

Tabel 1. Subjek penelitian Berdasakan usia dan jenis kelamin

\begin{tabular}{|c|c|c|c|c|c|c|}
\hline \multirow{3}{*}{$\begin{array}{c}\text { Jenis } \\
\text { Kelamin }\end{array}$} & \multicolumn{6}{|c|}{ Usia } \\
\hline & \multicolumn{2}{|c|}{$\begin{array}{c}12 \\
\text { Tahun }\end{array}$} & \multicolumn{2}{|c|}{$\begin{array}{c}13 \\
\text { Tahun }\end{array}$} & \multicolumn{2}{|c|}{ Total } \\
\hline & $\mathrm{n}$ & $\%$ & $\mathrm{n}$ & $\%$ & $\mathrm{n}$ & $\%$ \\
\hline Laki-laki & 22 & 39 & 7 & 12 & 29 & 51 \\
\hline Perempuan & 20 & 35 & 8 & 14 & 28 & 49 \\
\hline Jumlah & 42 & 74 & 15 & 26 & 57 & 100 \\
\hline
\end{tabular}

Dari hasil pemeriksaan DMF-T pada anak SMP Santo Yohanis Penginjil Desa Laikit Minahasa Utara, jumlah indeks D (decayed) 107, M (missing) 8 dan $\mathrm{F}$ (filling) 4. Jumlah indeks DMF-T rata-rata yang di dapat dari 57 responden di SMP Santo Yohanis Santo Penginjil Desa Laikit ialah 2 dalam kriteria WHO masuk dalam kategori rendah. Data pada Tabel 2. Menunjukkan indeks DMF-T jenis kelamin laki-laki lebih tinggi dibandingkan jenis kelamin perempuan.

Tabel 2. Distribusi masing-masing komponen DMF-T berdasarkan jenis kelamin

\begin{tabular}{|c|c|c|c|c|c|}
\hline \multirow{2}{*}{$\begin{array}{c}\text { Jenis } \\
\text { Kelamin }\end{array}$} & \multicolumn{3}{|c|}{ Komponen } & \multirow[t]{2}{*}{ Skor } & \multirow[t]{2}{*}{ Kategori } \\
\hline & $\mathrm{D}$ & M & $\mathrm{F}$ & & \\
\hline Laki-laki & 61 & 2 & 3 & 2,1 & Rendah \\
\hline Perempuan & 46 & 6 & 1 & 1,8 & Rendah \\
\hline Total & 107 & 8 & 4 & 2 & Rendah \\
\hline
\end{tabular}

Data pada Tabel 3 menunjukkan subjek penelitian berdasarkan jenis kelamin pada anak laki-laki berjumlah 29 orang (51\%) dan indeks DMF-T kategori sedang merupakan persentase terbanyak berjumlah 12 orang (21\%). Pada anak perempuan berjumlah 28 orang (49\%) persentase terbanyak terdapat pada kategori sangat rendah 14 orang (25\%). Dari hasil pemeriksaan OHI-S pada anak SMP Santo Yohanis Penginjil Desa Laikit Minahasa Utara jumlah indeks OHI-S rata-rata yang di dapat dari 57 responden di SMP Santo Yohanis Santo Penginjil Desa Laikit ialah 1,4 dalam kriteria WHO masuk dalam kategori sedang.

Tabel 3. Subjek penelitian status karies berdasarkan jenis kelamin

\begin{tabular}{cccccccccccccc}
\hline Jenis Kelamin & \multicolumn{11}{c}{ Status Karies } \\
\cline { 2 - 15 } & $\begin{array}{c}\text { Sangat } \\
\text { Rendah }\end{array}$ & Rendah & Sedang & Tinggi & $\begin{array}{c}\text { Sangat } \\
\text { Tinggi }\end{array}$ & Total \\
\cline { 2 - 15 } & $\mathrm{n}$ & $\%$ & $\mathrm{n}$ & $\%$ & $\mathrm{n}$ & $\%$ & $\mathrm{n}$ & $\%$ & $\mathrm{n}$ & $\%$ & $\mathrm{n}$ & $\%$ \\
\hline Laki-laki & 9 & 16 & 8 & 14 & 12 & 21 & 0 & 0 & 0 & 0 & 29 & 51 \\
Perempuan & 14 & 25 & 2 & 4 & 11 & 19 & 0 & 0 & 1 & 2 & 28 & 49 \\
Jumlah & 23 & 40 & 10 & 18 & 23 & 40 & 0 & 0 & 1 & 2 & 57 & 100 \\
\hline
\end{tabular}


Dengah, Mariati, Juliatri: Gambaran tingkat karies...

Tabel 4. Distribusi indeks OHI-S berdasarkan jenis kelamin

\begin{tabular}{cccc}
\hline $\begin{array}{c}\text { Jenis } \\
\text { Kelamin }\end{array}$ & Skor & OHI-S & Kategori \\
\hline Laki-laki & 46,8 & 1,6 & Sedang \\
Perempuan & 37,7 & 1,3 & Sedang \\
Jumlah & 84,5 & 1,4 & Sedang \\
\hline
\end{tabular}

Data pada Tabel 5 menunjukkan bahwa dari 57 subjek penelitian yang dinilai menggunakan OHI-S terdapat hasil status kebersihan gigi dan mulut dengan kriteria baik persentase terbanyak dimiliki oleh 12 anak laki-laki (21\%). Subjek penelitian dengan kriteria status kebersihan gigi dan mulut sedang dengan persentase terbanyak berjumlah 17 anak perempuan (30\%).

Data pada Tabel 6 menunjukkan subjek penelitian dengan DMF-T sedang memiliki presentase terbanyak dengan disertai status kebersihan gigi dan mulut terdapat pada kategori sedang berjumlah 13 orang

(22\%).

Tabel 5. Subjek penelitian kategori OHI-S berdasarkan jenis kelamin

\begin{tabular}{ccccccccc}
\hline Jenis Kelamin & \multicolumn{8}{c}{ Kategori OHI-S } \\
\cline { 2 - 9 } & \multicolumn{2}{c}{ Baik } & \multicolumn{2}{c}{ Sedang } & \multicolumn{3}{c}{ Buruk } & \multicolumn{2}{c}{ Total } \\
\cline { 2 - 8 } & $\mathrm{n}$ & $\%$ & $\mathrm{n}$ & $\%$ & $\mathrm{n}$ & $\%$ & $\mathrm{n}$ & $\%$ \\
\hline Laki-laki & 12 & 21 & 13 & 23 & 4 & 7 & 29 & 51 \\
Perempuan & 10 & 17 & 17 & 30 & 1 & 2 & 28 & 49 \\
Jumlah & 22 & 39 & 30 & 52 & 5 & 9 & 57 & 100 \\
\hline
\end{tabular}

Tabel 6. Subjek penelitian karies berdasarkan OHI-S

\begin{tabular}{ccccccccc}
\hline Status Karies & \multicolumn{10}{c}{ Kategori OHI-S } \\
\cline { 2 - 10 } & \multicolumn{2}{c}{ Baik } & \multicolumn{1}{c}{ Sedang } & \multicolumn{2}{c}{ Buruk } & \multicolumn{2}{c}{ Total } \\
\cline { 2 - 10 } & $\mathrm{n}$ & $\mathrm{n}$ & $\%$ & $\mathrm{n}$ & $\%$ & $\mathrm{n}$ & $\%$ \\
\hline Sangat rendah & 11 & 19 & 12 & 21 & 0 & 0 & 23 & 40 \\
Rendah & 2 & 3 & 4 & 7 & 4 & 7 & 10 & 18 \\
Sedang & 9 & 16 & 13 & 22 & 1 & 2 & 23 & 40 \\
Tinggi & 0 & 0 & 0 & 0 & 0 & 0 & 0 & 0 \\
Sangat Tinggi & 0 & 0 & 1 & 2 & 0 & 0 & 1 & 2 \\
Jumlah & 22 & 39 & 30 & 52 & 5 & 9 & 57 & 100 \\
\hline
\end{tabular}

\section{BAHASAN}

Berdasarkan hasil penelitian pada Tabel 2 menunjukkan hasil pemeriksaan karies berdasarkan DMF-T, rata-rata DMF$\mathrm{T}$ siswa SMP Santo Yohanis Penginjil adalah 2. Nilai rata-rata DMF-T tersebut masuk dalam kategori rendah. Berdasarkan hasil penelitian indeks DMF-T lebih banyak dimiliki oleh anak laki-laki dibandingkan perempuan, dapat dilihat pada Tabel 3. dari 57 subjek penelitian yang berjenis kelamin laki-laki sebanyak 9 orang (16\%) kategori sangat rendah, 8 orang (14\%) kategori rendah, 12 orang (21\%) kategori sedang, dan tidak ada siswa yang memiliki kategori tinggi dan sangat tinggi. Jenis kelamin perempuan sebanyak 14 orang (25\%) kategori sangat rendah, 2 orang (4\%) kategori rendah, 11 siswa (19\%) kategori sedang, tidak ada siswa yg masuk dalam kategori tinggi dan 1 orang (2\%) kategori sangat tinggi. Hasil 
pemeriksaan karies berdasarkan jenis kelamin yaitu jenis kelamin laki-laki memiliki DMF-T rata-rata 2,1 masuk dalam kategori rendah. Jenis kelamin perempuan memilki DMF-T rata-rata 1,8 masuk kategori rendah. Pada penelitian ini, terdapat tingkat karies yang lebih tinggi pada anak laki-laki dibandingkan perempuan karena menurut asumsi peneliti anak laki-laki kurang memperhatikan pemeliharaan kebersihan giginya sehingga tidak rajin menggosok gigi. Penelitian yang dilakukan oleh Indry di Manado, menunjukkan anak laki-laki memiliki ratarata DMF-T lebih tinggi daripada anak perempuan yaitu 3,86 dengan tingkat karies kategori sedang. Hal ini disebabkan lebih banyak anak perempuan yang memiliki kebiasaan menyikat gigi sebelum tidur. ${ }^{8}$ Berbeda dengan penelitian oleh Saima A, Saleem $M$ mengemukakan perempuan lebih tinggi DMF-T disebabkan oleh perilaku pemeliharaan dan asupan makanan. $^{9}$

Berdasarkan hasil penelitian dapat dilihat pada Tabel 4 OHI-S rata-rata yaitu 1,4 masuk dalam kategori sedang. Berdasarkan hasil penelitian pada Tabel 5 menunjukkan hasil pemeriksaan OHI-S, sejumlah 22 orang (39\%) memiliki kriteria status kebersihan gigi dan mulut baik, 30 orang (52\%) memiliki kriteria status kebersihan gigi dan mulut sedang dan 5 orang (9\%) memiliki kriteria kebersihan gigi dan mulut buruk. Penelitian yang dilakukan Kuwait pada usia 5-14 tahun 3,9\% memiliki kategori baik, 67\% sedang dan 29,1\% termasuk dalam kategori buruk dan nilai OHI-S rata-rata yaitu 1,5 merupakan kategori sedang. ${ }^{10}$ Hasil penelitian pada siswa SMP Santo Yohanis Penginjil Laikit menunjukkan bahwa masih rendahnya presentase kebersihan gigi dan mulut baik dan persentase tertinggi pada kategori sedang menunjukkan pada umumnya sebagian siswa sudah bisa menjaga kebersihan mulutnya, namun perlu lebih ditingkatkan kesadaran dan pemeliharaan kebersihan gigi dan mulut. Subjek penelitian dengan jenis kelamin laki-laki sebanyak 12 orang (21\%) kategori baik, 13 orang (23\%) kategori sedang, dan 4 orang $(7 \%)$ memiliki kategori buruk. Subjek penelitian dengan jenis kelamin perempuan sebanyak 10 orang (17\%) kategori baik, 17 orang (28\%) kategori sedang, dan 1 orang (2\%) memiliki kategori buruk. Penilaian OHI-S pada siswa laki-laki dan perempuan menunjukkan nilai status kebersihan gigi dan mulut yang hampir sama, akan tetapi siswa lakilaki memiliki nilai OHI-S rata-rata lebih tinggi yaitu 1,6 dibandingkan perempuan yang memiliki nilai OHI-S rata-rata 1,3. Anak-anak perempuan memiliki keadaan kebersihan gigi dan mulut yang lebih baik dibandingkan anak laki-laki. Hal ini disebabkan anak perempuan lebih mementingkan dan memiliki kesadaran yang tinggi akan estetik dan pemeliharaan kebersihan giginya.

Hasil Penelitian di Kuwait juga menunjukkan nilai indeks OHI-S yang tidak jauh berbeda, nilai OHI-S lebih tinggi untuk anak laki-laki dibandingkan perempuan (rata-rata skor 1,6 banding 1,5). ${ }^{10}$ Hal ini sama dengan penelitianpenelitian yang dilakukan pada remajaremaja di Jepang dan Kenya yang menyatakan bahwa perilaku perawatan kesehatan gigi dan mulut anak perempuan lebih baik dari pada anak laki-laki. ${ }^{11,12}$

Berdasarkan hasil penelitian pada Tabel 6, menunjukkan bahwa Hasil pemeriksaan karies berdasarkan DMF-T menunjukkan kategori sangat rendah memiliki kriteria kebersihan gigi dan mulut sedang yang berjumlah 12 orang (21\%), Pemeriksaan karies berdasarkan DMF-T kategori rendah memiliki kriteria status kebersihan gigi dan mulut buruk berjumlah 4 orang (7\%), karies berdasarkan DMF-T kategori sedang memiliki kriteria status kebersihan gigi dan mulut sedang berjumlah 13 orang (22\%), dan tidak ada siswa yang memiliki karies dengan kategori tinggi. Pemeriksaan karies berdasarkan DMF-T menunjukkan kategori karies sangat tinggi memiliki status kebersihan gigi dan mulut sedang yaitu berjumlah 1 orang (2\%).

Hasil penelitian ini menunjukkan 
bahwa tingginya angka prevalensi karies gigi disebabkan oleh kebersihan gigi dan mulut yang buruk. Kebersihan gigi dan mulut seseorang memengaruhi terjadinya karies karena kurangnya kesadaran dan perhatian terhadap kesehatan gigi dan mulut. Faktor pendukung terjadinya karies gigi pada anak juga dipengaruhi oleh makanan dan minuman dan disertai dengan kebiasaan yang buruk.

\section{SIMPULAN}

Dari hasil penelitian terhadap siswa SMP Santo Yohanis Penginjil Desa Laikit Minahasa Utara dapat disimpulkan status karies siswa yaitu 2 (indeks DMF-T kategori rendah). Status karies siswa pada siswa laki-laki yaitu 2,1 dan perempuan yaitu 1,8 (indeks DMF-T kategori rendah). Status kebersihan gigi dan mulut siswa yaitu 1,4 (indeks OHI-S kategori sedang). Status kebersihan gigi dan mulut siswa laki-laki yaitu 1,6 dan siswa perempuan 1,3 (indeks OHI-S kategori sedang).

Persentase terbanyak pemeriksaan karies berdasarkan kebersihan gigi dan mulut terdapat pada kategori sedang (22\%).

\section{SARAN}

Diharapkan pemerintah untuk lebih memerhatikan derajat kesehatan gigi dan mulut pada kelompok usia remaja dengan meningkatkan program kesehatan gigi dan mulut, serta penyediaan sarana dan prasarana untuk menunjang pelaksanaan program tersebut.

Diharapkan sekolah agar lebih memotivasi dan memperhatikan derajat kebersihan gigi dan mulut siswa, melalui program-program dari sekolah itu sendiri, juga diharapkan bagi sekolah untuk mengadakan penyuluhan kesehatan gigi dan mulut. Diharapkan orang tua dapat memberikan perhatian lebih dan memberikan contoh perilaku pemeliharaan kebersihan gigi dan mulut yang benar.

\section{DAFTAR PUSTAKA}

1. Angela A. Pencegahan primer pada anak yang beresiko karies tinggi. Dent J, 2009:38 (3):130.
2. Pintauli S, Hamada T. Menuju gigi dan mulut sehat.. Medan: USU Press, 2009; p.1-6, 15-6,29-30, 70-84.

3. World Health Organisation. Media centre oral health. [online]. [cited April 2012]. Available from: http://www.who.int/mediacentre/facts heets/fs318/en.

4. Riset Kesehatan Dasar. Badan penelitian dan pengembangan kesehatan Departemen Kesehatan, Republik Indonesia. Jakarta; Laporan Nasional,: 2013.

5. Lindhe J, Lang NP, Karring T. Clinical periodontology and implant denstistry (5th ed.). New York: Blackwell Munksgaard, 2008; p. 133-96.

6. WHO Oral Health Country Area Profile Programme. Oral hygiene simplifiedgreene and vermillion, 1964. [cited 2011 Nov 10]. p. 2-4. Available from: www.whocollab.od.mah.se/expl/ohis gv64.html.

7. Wowor V. Hubungan antara status kebersihan mulut dengan karies siswa sekolah menengah atas Negeri 1 Manado. Manado: Universitas Sam Ratulangi; 2012.

8. Worotitjan I. Pengalaman karies gigi serta pola makan dan minum pada anak sekolah dasar di Desa Kiawa Kecamatan Kawangkoan Utara. Manado: Universitas Sam Ratulangi; 2013.

9. Saima A, Saleem M, Mohtada H, Fatima I. Distribution of dental caries and its relationship to risk factors. Pakistan oral \& dental journal. 2011:31(2):453-6. http://www.podj.com.pk/Dec_2011/5 2-Podj.pdf

10. Mutawa S.A, Shyamma M, Duwairi Y, Soparkar P. Oral hygiene status of Kuwaiti schoolchildren. 2011;17(5): 387-91. Available from: http://applications.emro.who.int/emhj /V17/05/175201103870391.pdf

11.Kawamura $M$, Takase $N$, Sasahara $H$, Okada M. Teenangers oral health attitudes and behavior in japan: Comparison by sex and age group. Journal of Oral science. 2008;50(2). Available from: http://www.ncbi.nlm.nih.gov/pubmed $/ 15330998$ 
Jurnal e-GiGi (eG), Volume 3, Nomor 2, Juli-Desember 2015

12. Kemwa KA, Rotich JK. The oral health knowledge and oral hygiene practices among primary school children age 517 years in a rural area of Uasin Gishu district, Kenya. East African
Journal of Public Health. 20107(2)187-90. Available from: http://www.ncbi.nlm.nih.gov.pubmed $/ 21413602$ 